\title{
Possible failure of novel direct-acting oral anticoagulants in management of pulmonary embolism: a case report
}

\author{
James Rankin ${ }^{1 *}$, Menachem Nagar ${ }^{1}$, Jonathan Crosby ${ }^{1}$, Nojan Toomari ${ }^{1}$, Richard Pietras $^{2}$ and Uri M. Ben-Zur ${ }^{1,2}$
}

\begin{abstract}
Background: The relative effectiveness of vitamin $\mathrm{K}$ antagonists compared with novel oral anticoagulants in treating pulmonary embolism remains unclear. Recent trials comparing the efficacy of vitamin K antagonists with factor Xa inhibitors for the treatment of pulmonary emboli have been non-inferiority studies based primarily on risk reduction (such as bleeding events), rather than resolution of specific diseases such as pulmonary embolism. Consequently, there is a lack of evidence indicating which of these agents are more effective. Here, we present a case where pulmonary emboli were treated with novel oral anticoagulants followed by warfarin to discuss the potential limitations in the use of novel oral anticoagulants as prevention or treatment of thromboembolism and the continued role for warfarin in this setting.

Case presentation: A 34-year-old African American woman presented to our clinic with shortness of breath and pleuritic chest pain several months post-surgery. She was identified as having multiple bilateral pulmonary embolisms and was treated with several novel oral anticoagulants, which failed to resolve the clots. Complete resolution was achieved upon switching to warfarin.

Conclusions: The patient described in this report failed to respond to novel oral anticoagulant therapy, but her emboli resolved when she was treated with warfarin. This study challenges the notion that factor Xa inhibitors are better alternatives to vitamin $\mathrm{K}$ anticoagulants in the treatment of pulmonary emboli based on their safety profile and ease of use alone. As a result, further post-marketing investigations into the efficacy of these agents in the management of pulmonary emboli may be warranted.
\end{abstract}

Keywords: Anticoagulant therapy, Warfarin, Factor Xa inhibitor, Thrombosis, Embolism, Case report

\section{Background}

Venous thromboembolism (VTE) is a condition that comprises deep vein thrombosis (DVT) with or without the presence of systemically circulating emboli; it includes conditions such as pulmonary embolism (PE). Prevention and treatment of VTE are imperative due to the significant morbidity and risk of mortality involved. Currently, agents available to treat this condition are limited and, among these, the mainstay of both prevention and treatment for over 60 years has been warfarin (Coumadin $^{\circ}$; also Jantoven ${ }^{\circ}$ and Marevan $^{\circ}$ ), which is an oral vitamin $\mathrm{K}$ antagonist (VKA). However, warfarin

\footnotetext{
*Correspondence: rankinjs@gmail.com

'Division of Cardiology, Providence-Tarzana Medical Center, Tarzana, CA 91356, USA

Full list of author information is available at the end of the article
}

treatment is inconvenient due to its increased risk of adverse events (that is, bleeding), which makes it an undesirable option $[1,2]$.

In response, new agents were developed to improve patients' quality of life and to decrease the risk of bleeding in those requiring long-term anticoagulation. One class of these newer agents, the novel oral anticoagulants (NOACs) including direct factor $\mathrm{Xa}$ inhibitors (FXaI) and direct thrombin inhibitors, is quickly becoming the standard of care as first-line agents due to clear advantages with regard to monitoring and risks of adverse events. However, at this point, there is limited long-term data to determine all factors for their use in special circumstances. Here we present a case of a medicationcompliant patient who experienced recurrent pulmonary emboli, yet failed to resolve these emboli on initial 
treatment with multiple NOACs, reaching complete resolution of emboli only after being switched to warfarin treatment.

\section{Case presentation}

Our patient is a 34-year-old obese (body mass index, BMI, $31.09 \mathrm{~kg} / \mathrm{m}^{2}$ ) African American woman with a history of an undefined congenital septal defect, the status of which is post-surgical repair, and congenital clubfoot, who also underwent calcaneal tendon repair in May of 2015. Afterward, she remained sedentary for several weeks and then began to report progressively worsening non-exertional dyspnea that was associated with sharp intermittent chest pain. On 31 May 2015, she presented to her local emergency department for dyspnea on inspiration and "stabbing" pleuritic chest pain at bilateral lung bases. A computed tomography (CT) angiogram of her chest was performed, demonstrating multiple bilateral PEs (Fig. 1). She was then admitted to a hospital and started on rivaroxaban (Xarelto ${ }^{\circ}$, Janssen) dosed at $15 \mathrm{mg}$ administered orally once a day. In September 2015, despite compliance with her rivaroxaban therapy for several months, a ventilation-perfusion (V/Q) scan demonstrated multiple bilateral pulmonary emboli. Rivaroxaban was discontinued and she was switched to dabigatran (Pradaxa ${ }^{\circ}$, Boehringer Ingelheim) $150 \mathrm{mg}$ administered orally twice daily. Within a few days, she developed acute severe hip joint pain. She was then switched to apixaban (Eliquis ${ }^{\oplus}$, Bristol-Myers Squibb) at
$5 \mathrm{mg}$ administered orally twice daily. On a follow-up V/Q scan in January 2016, she was found to have persistent PEs; she was then referred to our clinic.

Based on prior studies, apixaban was discontinued and warfarin therapy was initiated at $10 \mathrm{mg}$ administered orally one a day with a goal of international normalized ratio (INR) 2.0-3.0, requiring weekly INR checks with appropriate dosing adjustments. She reported gradual progressive improvement and in March 2016 a CT angiography of her chest was performed with no evidence of pulmonary arterial thrombi or emboli (Fig. 2).

\section{Conclusions}

For over 60 years, warfarin has been the standard outpatient management option for VTE. It has proven efficacy for this indication, significantly decreasing thromboembolic events while maintaining an acceptable level of adverse events, primarily bleeding episodes $[1,3]$. This has been confirmed by numerous prospective studies and in post-marketing clinical use, including trials conducted to compare the efficacy of conventional doses of warfarin with low doses for providing anticoagulation. Conventional doses of warfarin (INR 2.0-3.0) were shown to provide superior treatment for VTE when compared with low-dose therapy (INR 1.5-1.9), notably with no significantly increased risk for "clinically important" bleeding [1]. However, warfarin use is not straightforward and requires: (a) bridging therapy (the use of parenteral anticoagulants until appropriate levels are attained), (b) frequent

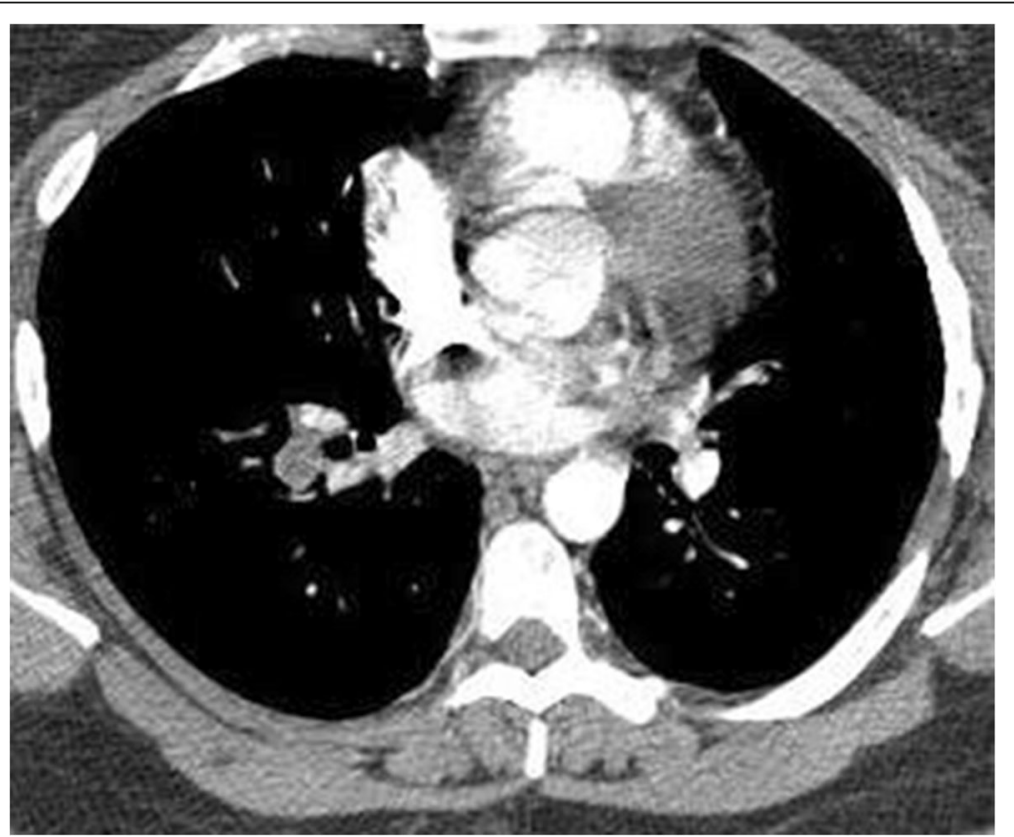

Fig. 1 Computed tomography angiography of the chest with right-sided arterial emboli. Coronal section of this patient's computed tomography angiography demonstrates a filling defect within the pulmonary vasculature, most likely representing emboli. At the time of this study, the patient was being treated with a novel oral anticoagulant (rivaroxaban) 


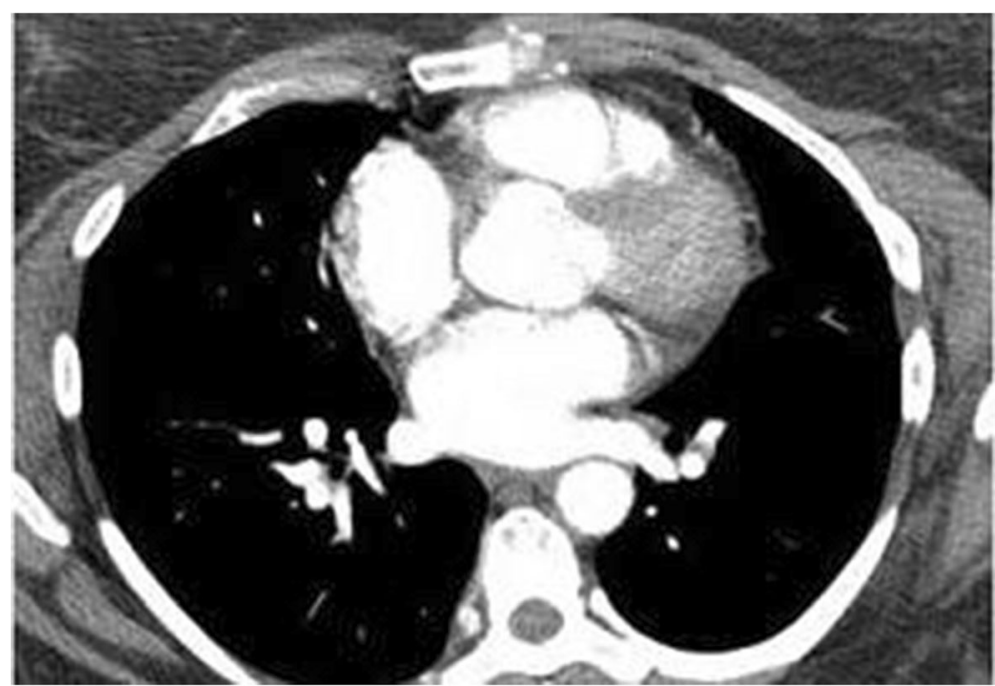

Fig. 2 Computed tomography angiography of the chest without any evidence of emboli. A follow-up computed tomography after discontinuation of novel oral anticoagulant therapy and initiation of closely monitored conventional warfarin anticoagulation (international normalized ratio 2.0-3.0). A coronal section of this study at the same level as Fig. 1 reveals vessels filled with intravenous contrast indicating patency without the presence of emboli

monitoring of individualized dosing to maintain INR levels within a narrow therapeutic window (in most instances, an INR goal between 2 and 3), and an (c) awareness of the significant risk of adverse bleeding events requiring potentially inconvenient lifestyle modifications [2]. Bleeding events associated with warfarin use range in severity from minor to fatal. One report indicated that warfarin elicited twice as many major bleeding episodes as placebo, while another found the incidence of major bleeding episodes in patients with a target INR greater than 3.0 to be twice as high as in those with a target between 2.0 and $3.0[4,5]$.

Alternatively, novel direct-acting oral anticoagulants aim to provide a safer, more tolerable, treatment option as compared to warfarin to prevent and treat DVT, PE, and atrial fibrillation (Afib) [3, 6]. Benefits of novel directacting oral anticoagulants include: (a) no need to monitor INR levels, and (b) potentially decreased drug interactions and adverse events (such as bleeding episodes). One family of novel direct-acting oral anticoagulants, the direct FXaIs, such as rivaroxaban (Xarelto ${ }^{\circ}$ ) and apixaban (Eliquis ${ }^{\circ}$ ), were only made available in the USA as recently as 2010 [7]. This family of drugs all share a similar mechanism of action, inhibiting the cleavage of prothrombin into thrombin during the final step of the common coagulation cascade. Several trials have compared FXaIs with warfarin in treating VTE. The EINSTEIN-PE trial showed rivaroxaban to be non-inferior to warfarin regarding $\mathrm{PE}$ treatment and demonstrated no difference in overall bleeding events [8]. Similarly, the AMPLIFY and Hokusai-VTE trials showed non-inferiority of apixaban and edoxaban, respectively, when compared with warfarin in the treatment of VTE, with a significant reduction in bleeding events $[9,10]$.

However, it is important to note that the trials reported to date have largely been non-inferiority studies, not equivalency or superiority studies. Data reported in the EINSTEIN-PE trial showed a downward trend in VTE episodes among those treated with warfarin versus rivaroxaban, but displayed a reduced number of bleeding episodes in the rivaroxaban group as compared with the warfarin group [8]. Most of these studies focused on treatment of VTE as a single category (DVT with or without non-fatal or fatal PEs), rather than reporting on the analysis of separate subsets (DVT, non-fatal PEs, fatal PEs, and so forth) contained within this larger group. Only one study, the EINSTEIN-PE trial, provided insight into the treatment of PE in isolation, revealing a trend toward superiority in warfarin-treated patients over FXaI in both non-fatal and fatal PE categories [8]. As a consequence of data available from these several recent trials, clinical guidelines, such as those of the "CHEST Guideline and Expert Panel Report", now recommend use of newer agents, such as dabigatran, rivaroxaban, apixaban and edoxaban, rather than VKAs to manage patients with lower extremity VTE [11].

It is clear that non-inferiority studies are useful to determine the general safety profile of a novel therapeutic agent while retaining the efficacy of an accepted therapeutic standard. However, the lack of equivalency or superiority data and the absence of findings in established subsets of affected patients impede a clinician's ability to critically evaluate what therapeutic agent may be best in 
treating specific conditions. Trials for new medications allow for the discovery and validation of agents, while decreasing potential risks, but these data should be regarded as tentative until more definitive studies have been performed in large populations, determining where the most benefit can be derived with the least possible risk.

It is accepted that common risk factors for clot formation include tobacco use, a history of coagulopathy, and/ or the use of oral contraception. The patient in this report was counseled on these risk factors and denied either a history of tobacco use or clotting dysfunction; however, she was determined to be on levonorgestrel-releasing intrauterine system (Skyla ${ }^{\circ}$, Bayer). Although intrauterine devices are impregnated with hormonal contraceptive agents and carry a risk of thrombosis, Skyla was not reported to induce any cases during clinical trials, only as a part of post-marketing studies, and she developed clots after long-term use of this device [12].

Without significant retrospective analyses or randomized prospective trials with subgroup analyses, it is difficult to determine whether VKAs or FXaIs are truly more effective in the treatment of PE. This assessment is especially difficult when taking into account the diagnostic modalities and treatments provided for this patient prior to arrival in our clinic. Although she was initially followed with serial V/Q scans to determine the success of her treatments, the EINSTEIN-PE investigators and our clinic elected to use CT angiography in view of its substantially increased resolution [8]. In addition, prior to arrival in our clinic, she was treated with rivaroxaban at $15 \mathrm{mg}$ administered orally once a day, as opposed to the generally recommended initial dose of $20 \mathrm{mg}$ administered orally, followed by $15 \mathrm{mg}$ administered orally twice a day [13]. In the case of rivaroxaban, in particular, these are important variables, because it is difficult to ascertain the effectiveness of a treatment if the standard of care is not being followed. However, the patient in this report was later managed with dabigatran and apixaban in accord with the recommended guidelines $[14,15]$.

We suggest that further investigations are needed to establish if novel direct-acting oral anticoagulants are equal to warfarin in the prevention and treatment of VTEs, including DVT and PE. Further, we suggest that practitioners carefully weigh the risks and benefits when selecting these medications. We note that Rudd et al. have reported independently on possible rivaroxaban failure in patients treated during the postpartum period, possibly due to pharmacokinetic alterations seen in the postpartum period that can contribute to decreased drug exposure and reduced anticoagulant efficacy [16]. In fact, rivaroxaban is well known to be metabolized by the cytochrome P450 isoenzyme CYP 3A4 and binds to Pglycoprotein; hence, leading to risks of pharmacokinetic interactions that may alter its anticoagulant properties [17]. In practice, it may be best at this time to choose between these several available anticoagulant drugs on a case-by-case basis, taking into account patient preferences, monitoring constraints, difficulty controlling the INR, the risk of bleeding and interactions, and the cost of treatment [18].

\section{Abbreviations}

Afib: Atrial fibrillation; BMI: Body mass index; CT: Computed tomography; DVT: Deep vein thrombosis; FXal: Factor Xa inhibitor; INR: International normalized ratio; NOAC: Novel oral anticoagulant; PE: Pulmonary embolism; VKA: Vitamin K antagonist; V/Q: Ventilation-perfusion; VTE: Venous thromboembolism

\section{Acknowledgements}

This work was done with the support of Uri Ben-Zur, MD and the Cardiovascular Institute of Los Angeles, both instrumental in helping to make this work possible.

\section{Funding}

All funding for this study was provided by U. Ben-Zur, MD, FACC. No outside funding was obtained.

\section{Availability of data and materials Not applicable.}

\section{Authors' contributions \\ $J R$ acquired the data, prepared the clinical information, and was the main contributor in drafting the manuscript. MN assisted in drafting the manuscript and providing revisions. JC assisted in acquiring and preparing the clinical information and providing revisions. NT, RP, and UB were all instrumental in drafting the manuscript and providing feedback. UB provided guidance in this process and designed the use of this case and the format. All authors read and approved the final manuscript.}

\section{Competing interests}

The authors declare that they have no competing interests.

\section{Consent for publication}

Written informed consent was obtained from the patient for publication of this case report and any accompanying images. A copy of the written consent is available for review by the Editor-in-Chief of this journal.

Ethics approval and consent to participate Not applicable.

\section{Author details}

${ }^{1}$ Division of Cardiology, Providence-Tarzana Medical Center, Tarzana, CA 91356, USA. Department of Medicine, UCLA David Geffen School of Medicine, Los Angeles, CA 90095, USA.

Received: 5 September 2016 Accepted: 7 November 2016 Published online: 03 December 2016

\section{References}

1. Kearon C, Ginsberg JS, Kovacs MJ, Anderson DR, Wells P, Julian JA, Mackinnon B, Weitz Jl, Crowther MA, Dolan S, Turpie AG, Geerts W, Solymoss S, van Nguyen P, Demers C, Kahn SR, Kassis J, Rodger M, Hambleton J, Gent M, Extended Low-Intensity Anticoagulation for Thrombo-Embolism Investigators. Comparison of low-intensity warfarin therapy with conventional-intensity warfarin therapy for long-term prevention of recurrent venous thromboembolism. N Engl J Med. 2003:349:631-9.

2. Ridker PM, Goldhaber SZ, Danielson E, Rosenberg Y, Eby CS, Deitcher SR, Cushman M, Moll S, Kessler CM, Elliott CG, Paulson R, Wong T, Bauer KA, Schwartz BA, Miletich JP, Bounameaux H, Glynn RJ. Long-Term, LowIntensity Warfarin Therapy for the Prevention of Recurrent Venous Thromboembolism. N Engl J Med. 2003;348:1425-34. 
3. Clayville LR, Anderson KV, Miller SA, St. Onge EL. New Options in Anticoagulation for the Prevention of Venous Thromboembolism and Stroke. Pharm Ther. 2011;36:86-99.

4. Schulman S, Kakkar AK, Goldhaber SZ, Schellong S, Eriksson H, Mismetti P, Christiansen AV, Friedman J, Le Maulf F, Peter N, Kearon C, for the RE-COVER II Trial Investigators. Treatment of Acute Venous Thromboembolism with Dabigatran or Warfarin and Pooled Analysis. Circulation. 2014;129:764-72.

5. Molteni M, Cimminiello C. Warfarin and atrial fibrillation: from ideal to real the warfarin affaire. Thromb J. 2014;12:5.

6. Dobesh PP, Fanikos J. New Oral Anticoagulants for the Treatment of Venous Thromboembolism: Understanding Differences and Similarities. Drugs. 2014; 74:2015-32.

7. Cabral KP, Ansell JE. The role of factor Xa inhibitors in venous thromboembolism treatment. Vasc Health Risk Manag. 2015;11:117-23.

8. The EINSTEIN-PE Investigators. Oral Rivaroxaban for the Treatment of Symptomatic Pulmonary Embolism. N Engl J Med. 2012;366:1287-97.

9. Hokusai-VTE Investigators, Büller HR, Décousus H, Grosso MA, Mercuri M, Middeldorp S, Prins MH, Raskob GE, Schellong SM, Schwocho L, Segers A, Shi M, Verhamme P, Wells P. Edoxaban versus warfarin for the treatment of symptomatic venous thromboembolism. N Engl J Med. 2013:369:1406-15.

10. Agnelli G, Buller HR, Cohen A, Curto M, Gallus AS, Johnson M, Masiukiewicz U, Pak R, Thompson J, Raskob GE, Weitz J. AMPLIFY Investigators. Oral apixaban for the treatment of acute venous thromboembolism. N Engl J Med. 2013;369:799-808.

11. Kearon C, Akl EA, Ornelas J, Blaivas A, Jimenez D, Bounameaux H, Huisman M, King CS, Morris TA, Sood N, Stevens SM, Vintch JRE, Wells P, Woller SC, Moores L. Antithrombotic Therapy for VTE Disease: CHEST Guideline and Expert Panel Report. Chest. 2016;149:315-52.

12. Bayer HealthCare Pharmaceuticals Inc.: SKYLA (levonorgestrel-Releasing Intrauterine System). Whippany, NJ; 2013. https://dailymed.nlm.nih.gov/ dailymed/druglnfo.cfm?setid=9f44ff35-e052-49cd-a1c2-0bfd87d49309.

13. Janssen: Xarelto (rivaroxaban). Titusville, NJ; 2014. https://dailymed.nlm.nih. gov/dailymed/druglnfo.cfm?setid=10db92f9-2300-4a80-836b-673e1ae91610.

14. Bristol-Myers Squibb: Eliquis (apixaban) Oral Tablets Prescribing Information. Princeton, NJ; 2014. https://dailymed.n/m.nih.gov/dailymed/druglnfo. cfm?setid=e9481622-7cc6-418a-acb6-c5450daae9b0.

15. Boehringer Ingelheim: Pradaxa (dabigatran Etexilate Mesylate). Ridgefield, CT; Aug 2014. https://dailymed.nlm.nih.gov/dailymed/druglnfo.cfm?setid= ba74e3cd-b06f-4145-b284-5fd6b84ff3c9.

16. Rudd KM, Winans ARM, Panneerselvam N. Possible Rivaroxaban Failure during the Postpartum Period. Pharmacotherapy. 2015;35:e164-168.

17. Nutescu EA, Burnett A, Fanikos J, Spinler S, Wittkowsky A. Pharmacology of anticoagulants used in the treatment of venous thromboembolism. J Thromb Thrombolysis. 2016:41:15-31.

18. Rivaroxaban: new drug. After hip or knee replacement surgery: LMWH is safer. Prescrire Int. 2009:18:151-3.

\section{Submit your next manuscript to BioMed Central and we will help you at every step:}

- We accept pre-submission inquiries

- Our selector tool helps you to find the most relevant journal

- We provide round the clock customer support

- Convenient online submission

- Thorough peer review

- Inclusion in PubMed and all major indexing services

- Maximum visibility for your research

Submit your manuscript at www.biomedcentral.com/submit 